\title{
Procesos de Reconocimiento e Interpretación de Unidades Fraseológicas Metafóricas y Factores Influyentes
}

\author{
Silvia Cataldo \\ Universidad de Alicante, San Vicente del Raspeig 03690, España \\ silvia.cataldo90@gmail.com
}

\begin{abstract}
Resumen. El objetivo de este trabajo es delinear un cuadro global de las modalidades de recepción de unidades fraseológicas metafóricas (idioms), presentando los factores que mayormente influyen en su detección e interpretación y en el esfuerzo cognitivo necesario para llevar a cabo estos procesos. Después de definir la metáfora como un mecanismo propio del pensamiento de conceptualizar la realidad de forma convencional o innovadora, que se manifiesta en la lengua a través de formulaciones libres o lexicalizadas, se introducen los idioms, unidades fraseológicas con valor figurado por expresar asociaciones entre dominios distintos. Los factores que intervienen en su reconocimiento y comprensión y en el esfuerzo cognitivo que estos suponen, son heterogéneos y guardan relación con una dimensión gramatical, una semántico-conceptual, la frecuencia de uso y el grado de familiaridad, el acceso directo al sentido figurado o la necesidad de analizar literalmente la expresión. Estos últimos dos en particular, influyen en los tiempos de comprensión y, a su vez, están relacionados con los aspectos mencionados anteriormente, además de con la ambigüedad de la expresión (si acepta más interpretaciones), la predictibilidad de las palabras que la componen y el contexto en el que ella aparece. Todos los factores señalados, como resulta claro, no son autónomos, sino que se entremezclan, creando una condición de dependencia recíproca.
\end{abstract}

Palabras clave: Idioms, Fraseología, Cognición.

\section{$1 \quad$ La Metáfora en la Mente}

A lo largo del siglo XX, poco a poco, se deja de concebir la metáfora como un fenómeno lingüístico con función decorativa, privilegiando su carácter cognitivo: a partir de las observaciones de Richards (1936), Black (1962), Lakoff y Johnson (1980), se propone una visión de la metáfora como mecanismo de transferencia de características entre dominios distintos, que puede ser convencional por un lado, si responde a formas de comprender una determinada realidad comunes en varias culturas, en una comunidad dada, en grupos reducidos dentro de ella o de una situación enunciativa en concreto, o incluso utilizadas normalmente por un solo individuo, (cf. Kövecses 2005; 2010a; 2010b; 2010c), e innovadora por otro lado. 
En el marco de este trabajo, se hará referencia a conceptualizaciones convencionales, sin considerar su grado de difusión intra- o intercultural.

\section{La Metáfora en la Lengua: los Idioms}

Las metáforas en la mente comentadas en el párrafo anterior se pueden manifestar en la lengua como formulaciones libres en caso de conceptualizaciones puntuales y como libres o lexicalizadas en correspondencia de conceptualizaciones convencionales. Estas últimas, a su vez, pueden constar de palabras sueltas, tal y como se observa en las polisemias, o de unidades fraseológicas, las cuales pueden incluso sufrir manipulaciones creativas internas, si se interviene en sus componentes, o externas, por ejemplo, si se insertan en un contexto inusual ( $c f$. Corpas 1996: 235-250; $c f$. Langlotz, 2006: 179-182). El presente estudio se concentra en las unidades fraseológicas con valor metafórico (denominadas también idioms) que no han sufrido modificaciones.

\section{Modalidades de Reconocimiento e Interpretación de Idioms}

En esta tercera sección se presentan algunos de los factores que influyen en el reconocimiento y en la interpretación de los idioms y en el esfuerzo cognitivo que dichos procesos mentales comportan. En primer lugar, se toma en consideración la relación cronológica, no siempre lineal y previsible, entre reconocimiento de la condición lexicalizada de la expresión y de su metaforicidad, e interpretación; en los subpárrafos sucesivos, en cambio, se tratan los aspectos gramaticales, semánticoconceptuales y relativos a la frecuencia de uso relacionados con la detectabilidad y con la correcta comprensión de los idioms; por último, se consideran los principales factores involucrados en el esfuerzo cognitivo requerido al oyente o al lector para el procesamiento de unidades fraseológicas metafóricas.

\subsection{Relación Cronológica entre Reconocimiento e Interpretación}

En lo que atañe a la relación cronológica entre el reconocimiento de una unidad fraseológica y su interpretación, Timofeeva (2012: 409-410) parafrasea, interpreta y completa la visión de Corpas (2003): la autora supone que cuando se conoce el significado de una unidad fraseológica figurada hay simultaneidad, mientras que con expresiones homófonas, que se pueden comprender tanto literal como metafóricamente, la interpretación puede preceder y guiar hacia la identificación; además, admite la posibilidad de que se detecte el fraseologismo a pesar de no conocer su significado y de que la identificación pueda incluso no tener lugar. Aunque Timofeeva delinea su reflexión en una óptica traductológica, su discurso podría adaptarse a cualquier lector, ya que el primer paso de una traducción es la lectura y la comprensión del texto. Por lo visto, resulta clara la incapacidad de establecer a priori si la detección se manifiesta y cuándo, tratándose de un proceso 
vinculado a factores subjetivos, relativos a la competencia fraseológica y a la sensibilidad lingüística del individuo, contextuales, gramaticales y semánticoconceptuales. Debido a esta imprevisibilidad, en el marco del presente trabajo, solo en ciertos casos se podrá distinguir entre reconocimiento e interpretación, mientras que en la mayoría de las circunstancias tales mecanismos se considerarán en bloque.

\subsection{Factores Gramaticales Involucrados en el Reconocimiento de los Idioms}

Con respecto a la dimensión formal, Goatly (1997: 78-88) considera lo importante que puede ser, en la identificación de una metáfora, la categoría gramatical del dominio utilizado para comprender una determinada realidad: si se trata de un nombre, la posibilidad de que se detecte la metáfora es alta, pero va reduciéndose gradualmente si la transferencia conceptual se activa mediante un verbo, un adjetivo, un adverbio o una preposición. Sería a través de preposiciones que se manifiesta la mayoría de las metáforas en las lenguas, debido a su capacidad de adaptarse a usos temporales y abstractos (Steen, 2011: 52). Aunque la aportación de Goatly parece más adecuada en caso de polisemias, no se excluye que pueda aplicarse también a los idioms, por lo menos cuando su significado es parcialmente composicional y su metaforicidad reside solo en una palabra: según su teoría, en ser el segundo plato de alguien, por ejemplo, por concentrarse la metáfora en un sintagma nominal a través del cual se alude al hecho de ser una persona la segunda opción para otra, la metaforicidad resulta quizás más fuerte que en las expresiones caer enfermo, utilizada para referirse al enfermar alguien, y no estar muy católico, con la que se alude a un mal estado de salud, donde el valor figurado del verbo caer y del adjetivo católico, aunque evidente, podría percibirse con menor vigor. Sin embargo, es importante precisar que la percepción de la metaforicidad en los casos mencionados está vinculada también a otros aspectos que se comentarán más adelante. En lo que se refiere a las demás categorías gramaticales, no es fácil encontrar unidades fraseológicas cuya metaforicidad derive de un adverbio, a no ser que se haga referencia a algunas colocaciones, o de una preposición. Considérese la colocación profundamente dormido, donde el carácter figurado del adverbio combinado con dormir para describir la intensidad del sueño, presenta un grado de lexicalización muy alto, que en ocasiones no permite detectar conscientemente la metáfora; de forma en parte análoga, la expresión en un santiamén, del todo figurada por indicar que algo se lleva a cabo o se realiza en muy poco tiempo, presenta, en su interior, un uso figurado de en en el que reside la conceptualización extremamente común del tiempo en términos de espacio.

En cuanto a la dimensión formal, además, Baker (1992: 65) sugiere que posibles estructuras agramaticales dentro de un idiom pueden señalar su condición de unidad fraseológica. 


\subsection{Factores Semántico-conceptuales Involucrados en el Reconocimiento y en la Interpretación de los Idioms}

De entre los factores semántico-conceptuales relevantes en la identificación de la condición figurada y en la interpretación de idioms, se pueden mencionar: a) el posible valor de falsedad de un enunciado, considerando que para Grice (1975) la metáfora, independientemente de su condición lexicalizada, representa una violación de la máxima de calidad, por querer el hablante decir algo diferente a lo que su enunciado expresa literalmente, contando con la colaboración del interlocutor en darle a sus palabras una interpretación coherente; b) el grado de metaforicidad de la expresión figurada, que a su vez es alto en presencia de asociaciones de dominios semánticamente distantes por pertenecer a campos semánticos diferentes, sobre todo si son uno concreto y uno abstracto, y de una clara contradictoriedad de la imagen (Goatly 1997), que se supone que podría dar lugar a un fuerte conflicto conceptual. Aunque idealmente el conflicto conceptual no debería manifestarse en los idioms, que por definición son estables en la lengua y responden a conceptualizaciones ya disponibles, su posible baja frecuencia de uso, o la familiaridad limitada por parte del oyente o del lector, podrían hacer que una expresión lexicalizada se perciba como contradictoria. Hay que tener en cuenta, a este propósito, que es difícil que un individuo conozca todas las unidades fraseológicas de su lengua, lo que puede conllevar que las identifique y las interprete correctamente gracias a la transparencia de la conceptualización, al contexto o a sus propias capacidades de crear relaciones conceptuales, que las identifique por motivos formales y no las sepa interpretar, que las interprete correctamente sin enterarse de su condición lexicalizada por considerarlas innovadoras en la mente y libres en la lengua.

El desconocimiento de un idiom, de su condición lexicalizada o de su significado por parte de un individuo, se podría también deber a la presencia de variantes diatópicas o diastráticas: es posible que en una lengua existan unidades fraseológicas metafóricas limitadas territorialmente o propias de ciertos grupos sociales, desconocidas en otras zonas o por personas no pertenecientes a esos grupos. La comprensión en tales circunstancias se parece de alguna forma a la que puede caracterizar la interpretación en la traducción, cuando las transferencias conceptuales disponibles en la lengua fuente y en la lengua meta son diferentes y el traductor se enfrenta con un idiom que no existe tal cual en la otra lengua y que no forma parte de su bagaje de conocimientos lingüísticos. Mandelblit (1995), al respecto, observa tiempos de reacción (y supuestamente esfuerzos cognitivos) menores en unidades fraseológicas que reflejan conceptualizaciones compartidas entre las lenguas involucradas en el proceso traductor, sobre todo si son análogas también lexicalmente, frente a las que reflejan conceptualizaciones distintas. Además de diferencias entre dos universos lingüístico-conceptuales, como pueden ser los representados no solo por dos lenguas, sino también por dos variantes de un mismo idioma, Bazzanella (1999: 155-156) sugiere que la falta de coincidencia de las experiencias de autor y lector hace que sus conceptualizaciones prototípicas de un determinado dominio sean distintas, originando dificultades en la interpretación o malentendidos. Esto, sin duda válido para las metáforas originales, puede aplicarse de alguna forma a las unidades 
fraseológicas figuradas: es posible, por ejemplo, que los hablantes de una misma lengua, en el uso y en la recepción de un idiom versátil, por ser capaz de adaptarse a más contextos, seleccionen preferentemente significados diferentes de entre los que se le suelen atribuir. Considérese la expresión española torcer la cabeza, que puede referirse tanto al enfermar como al morir: a no ser que el contexto desambigüe de manera inequivocable el sentido de la unidad fraseológica metonímica, por conceptualizar condiciones físicas mediante un posible gesto que las caracteriza habitualmente, dos individuos podrían propender por dos interpretaciones distintas dependiendo de si asocian con más frecuencia el movimiento de la cabeza a la enfermedad o a la muerte. De forma parecida, la expresión italiana fare la cicala (hacer la cigarra), podría aludir a la tendencia, por un lado, a gastar dinero sin pensar en el futuro, haciendo referencia a la fábula de la cigarra y de la hormiga, y por otro, a hablar mucho y de futilidades: también en este caso, sin el soporte del contexto, dos hablantes podrían no entenderse si uno acostumbra a conceptualizar la cigarra como un desperdiciador de riquezas y el otro como un gran hablador.

\subsection{Frecuencia de Uso y Grado de Familiaridad}

Algunos de los aspectos tratados en el párrafo anterior, además de adscribirse a los factores semántico-conceptuales mencionados, guardan cierta relación también con la frecuencia de uso de los idioms y con cuánto el receptor está familiarizado con ellos.

En primer lugar, es importante considerar que las unidades fraseológicas, a pesar de su fuerte estabilidad en la lengua, no presentan todas el mismo grado de difusión y algunas son utilizadas más a menudo que otras: claramente, las probabilidades de reconocimiento y adecuada interpretación serán superiores en las más comunes. Por otra parte, sin embargo, su alta frecuencia de uso podría obstaculizar la identificación de su carácter metafórico y llevar al oyente o al lector a acceder a su significado figurado sin percibir las transferencias conceptuales subyacentes. Se supone que existe un vínculo estricto entre frecuencia de uso del idiom y cuánto el individuo está familiarizado con él, aunque es cierto que el grado de familiaridad depende también de factores personales, ya que un hablante podría estar acostumbrado a utilizar preferentemente una unidad fraseológica determinada en general poco difusa y, por consiguiente, tener más posibilidades de reconocerla y comprenderla (o incluso de comprenderla sin percibir su metaforicidad) con respecto a otras personas.

\subsection{Esfuerzo Cognitivo}

En esta sección se trata el proceso de reconocimiento e interpretación de unidades fraseológicas metafóricas desde la perspectiva del esfuerzo cognitivo que este requiere al receptor. Varios estudiosos citados por Sjørup (2013), concentrándose en la comprensión de textos escritos, consideran que el esfuerzo cognitivo es directamente proporcional a la duración de la fijación ocular en la unidad textual, y por esto en los últimos años se han incrementado las investigaciones de eye-tracking, basadas en el seguimiento de los movimientos oculares del traductor en la pantalla. Aunque muchas de ellas se dedican a la observación de los aspectos cognitivos 
relacionados con la labor traductora, algunos de sus resultados se pueden aplicar al común lector.

Carpenter, Miyake y Just (1994: 1083), por ejemplo, observan que en correspondencia de expresiones ambiguas, la capacidad de la memoria de trabajo interviene en los tiempos necesarios para su procesamiento, ya que cuanto más reducida es, más se tarda en manejar las múltiples interpretaciones: esta es la situación que puede presentarse en caso de idioms que, en el contexto en el que aparecen, pueden adquirir claves de lectura distintas, literales y metafóricas o sólo metafóricas. Resumiendo los resultados de diferentes estudios y refiriéndose a la comprensión de textos en general, Sjørup (2013: 86-92) menciona varios elementos que se ha demostrado que influyen en el movimiento de los ojos, algunos de los cuales podrían considerarse válidos para los idioms: (i) ambigüedades léxicas o sintácticas, (ii) la ya mencionada escasa frecuencia de uso o familiaridad por parte del lector, en ambos casos con una duración mayor de las fijaciones oculares o un número más alto de ellas, (iii) predictibilidad de una palabra en un contexto determinado, que si es alta supone un esfuerzo cognitivo menor, con una reducción de los tiempos de fijación ocular, y que claramente dependerá también de cuánto el lector está familiarizado con la expresión.

El esfuerzo cognitivo, además, está vinculado al tipo de interpretación que se activa al empezar el procesamiento del idiom, que puede ser literal o metafórica. Según los partidarios de la standard pragmatic view, el receptor reconoce la metaforicidad de una expresión después de enterarse de la incoherencia de su significado literal, mientras que los que sostienen la direct access view, consideran que es posible acceder directamente al sentido figurado de ciertas expresiones. La primera parece respaldar la idea de Grice (1975) de que para interpretar correctamente una expresión metafórica, el oyente o el lector necesita identificarla como falsa, lo cual supondría tiempos de comprensión más largos; sin embargo, quienes sostienen la validez de la direct access view, afirman que en ocasiones se comprende una expresión en su sentido figurado incluso cuando esta podría aceptar una interpretación literal. Según Gibbs (1994: 425, 427), aunque pueda surgir del análisis semántico de los componentes, la interpretación metafórica podría no tener en cuenta el sentido literal de cada palabra: en un experimento, efectivamente, observa que con expresiones que admiten interpretaciones tanto idiomáticas como literales, se suele seleccionar el sentido convencional figurado y pasar a una comprensión literal solo si este no se considera plausible (Gibbs 1980: 155), como si algunos idioms estuvieran almacenados en la memoria como unidades léxicas. Sin embargo, el límite entre literalidad y metaforicidad en la interpretación de unidades fraseológicas figuradas parece matizado, ya que Cacciari y Tabossi (1988) y Cacciari (2001: 313-314) suponen la posibilidad de un análisis literal de los idioms hasta un punto de reconocimiento a partir del cual son procesados como bloques únicos.

Se ha observado también que la dimensión contextual juega un papel esencial tanto en la selección de una interpretación literal o metafórica, como en el acceso directo a esta en presencia de metáforas ambiguas y, por consiguiente, en el esfuerzo cognitivo por parte del lector: al respecto, Inhoff, Lima y Carroll (1984) han comprobado que un contexto amplio previo a la expresión metafórica permite comprenderla 
automáticamente en su sentido figurado, sin requerir tiempos superiores a los empleados en el procesamiento de un uso literal, y que estos se reducen si el contexto que precede la metáfora es metafórico y no literal. Aceptando todas las situaciones descritas por lo que atañe a la relación entre interpretaciones literales y metafóricas, se puede concluir que los tiempos de comprensión aumentan en caso de que se acceda al análisis semántico de los componentes para interpretar metafóricamente la unidad fraseológica, lo cual se traduce en un esfuerzo cognitivo mayor.

\section{Conclusiones}

Las reflexiones presentadas en este estudio pueden resumirse en los siguientes puntos: 1) la metáfora es un mecanismo de transferencias conceptuales de características entre dos dominios y 2) puede ser convencional o creativa en el pensamiento y realizarse de manera libre o lexicalizada en la lengua; 3 ) un tipo de metáforas lexicalizadas son los idioms, unidades fraseológicas de carácter figurado; 4) al procesar un idiom, el receptor podría detectarlo e interpretarlo simultáneamente, detectarlo antes de interpretarlo, interpretarlo antes de detectarlo, o interpretarlo sin reconocerlo como unidad fraseológica. 5) De entre los factores que intervienen en el procesamiento de los idioms, los que guardan relación con la detección de su condición metafórica y de su estado lexicalizado son respectivamente 5.1) la categoría gramatical del dominio utilizado para comprender una determinada realidad y 5.2) la composición interna en caso de estructuras gramaticalmente incorrectas, mientras que los que influyen en el reconocimiento de su condición figurada y en la interpretación son 5.3) aspectos semántico-cognitivos, relativos al posible valor de falsedad de una expresión y al grado de metaforicidad, que depende de la distancia semántica entre los dominios asociados y de la contradictoriedad de la imagen, y que está vinculado también al nivel de familiaridad del hablante con la expresión y a si para él esta refleja una conceptualización usual, sobre todo en caso de variantes diatópicas o diastráticas, 5.4) la frecuencia de uso y el grado de familiaridad del idiom, que si son altos podrían llevar a una correcta interpretación sin que se perciba la metaforicidad. 6) Estos aspectos intervienen en el esfuerzo cognitivo necesario para el procesamiento de una unidad fraseológica metafórica, cuya unidad de medida suele ser la duración del tiempo de fijación ocular durante la lectura, el cual depende también 6.1) de la ambigüedad de la expresión (si se puede interpretar tanto literal como metafóricamente), 6.2) de la predictibilidad de las palabras que componen el idiom y 6.3) de si su procesamiento empieza con una interpretación literal para luego pasar a una lectura metafórica o directamente con una comprensión figurada. En esta última cuestión juega un papel fundamental el contexto, además de factores personales como la competencia fraseológica del hablante (importante también para el reconocimiento

de la condición lexicalizada de la unidad textual), su nivel de familiaridad con la expresión y la frecuencia de uso del idiom.

De la breve lista presentada resulta evidente que los factores involucrados en la detección y en la interpretación de unidades fraseológicas metafóricas son 
heterogéneos y, al mismo tiempo, están estrictamente conectados y entremezclados entre ellos, lo cual hace que sea muy difícil prever la manera en la que el procesamiento de los idioms se realiza.

\section{Referencias}

1. Baker, M.: In Other Words: A Coursebook on Translation. Routledge, New York (1992).

2. Bazzanella, C.: La metafora tra mente e discorso: alcuni cenni. Lingua e stile, 34(2), 150158 (1999).

3. Black, M.: Models and metaphors: Studies in language and philosophy. Cornell University Press, Ithaca (1962).

4. Cacciari, C., P. Tabossi: The Comprehension of Idioms. Journal of Memory and Language 2, 668-683 (1988).

5. Cacciari, C.: Psicologia del linguaggio. Il Mulino, Bologna (2001).

6. Camp, E: Metaphor in the Mind: The Cognition of Metaphor. Philosophy Compass 1(2), 154-170 (2006)

7. Carpenter, P. A., A. Miyake, M. A. Just: Working memory constraints in comprehension: Evidence from individual differences, aphasia, and aging. In: Gernsbacher, M. A. (ed.) Handbook of Psycholinguistics, pp. 1075-1122. Academic Press, San Diego (1994).

8. Corpas Pastor, G.: Manual de fraseología española. Gredos, Madrid (1996).

9. Corpas Pastor, G: Diez años de investigación en fraseología: análisis sintácticosemánticos, contrastivos y traductológicos. Vervuert, Madrid (2003).

10. Gibbs, R.: The process of understanding literary metaphor. Journal of Literary Semantics 19, 65-94 (1990).

11. Gibbs, R.: Figurative Thought and figurative language. In: M. A. Gernsbacher (ed.) Handbook of Psycholinguistics, pp. 411-446. Academic Press, San Diego (1994).

12. Gibbs, R.: A new look at literal meaning in understanding what is said and implicated. Journal of Pragmatics 34, 457-486 (2002).

13. Gibbs, R.: Spilling the beans on understanding and memory for idioms in conversation. Memory \& Cognition 8, 149-156 (1980).

14. Goatly, A.: The language of metaphors. Routledge, London (1997).

15. Grice, H. P.: Logic and Conversation. In: Cole, P., J. L. Morgan (eds.) Syntax and Semantics 3: Speech Acts, pp. 41-58. Academic Press, New York: (1975).

16. Inhoff, A. W., S. D. Lima, P. J. Carroll: Contextual effects on metaphor comprehension in reading. Memory and Cognition 7(6), 558-567 (1984).

17. Kövecses, Z.: Metaphor in culture: universality and variation. Cambridge University Press, Cambridge (2005).

18. Kövecses, Z.: A new look at metaphorical creativity in cognitive linguistics. Cognitive Linguistics 21(4), 663-697 (2010a).

19. Kövecses, Z.: Metaphor and Culture. Acta Universitatis Sapientiae, Philologica 2(2), 197220 (2010b).

20. Kövecses, Z.: Metaphor, Creativity, and Discourse. DELTA 26, 719-738 (2010c).

21. Lakoff, G., M. Johnson: Metaphors we live by. The University of Chicago Press, Chicago/London (1980).

22. Langlotz, A.: Idiomatic Creativity. A cognitive-linguistic model of idiom-representation and idiom-variation in English. John Benjamins Publishing Company, Amsterdam \& Philadelphia (2006). 
23. Mandelblit, N.: The cognitive view of metaphor and its implications for translation theory. In: Thelen, M., B. Lewandowska-Tomaszczyk (eds.) TRANSLATION AND MEANING, Part 3, pp. 483-495. Hogeschool Maastricht, School of Translation and Interpreting, Maastricht (1995).

24. Richards, I. A.: The Philosophy of Rhetoric. Oxford University Press, New York/London (1936).

25. Sjørup, A. C.: Cognitive effort in metaphor translation. An eye-tracking and key-logging study. Copenhagen Business School, Copenhagen (2013).

26. Steen, G.: The Contemporary Theory of Metaphor: Now New and Improved! Review of Cognitive Linguistics 9(1), 26-64 (2011).

27. Timofeeva, L.: Sobre la traducción fraseológica. ELUA 26, 405-432 (2012). 